\title{
PERBANDINGAN PREMEDIKASI FENTANIL 1 mcg/kgBB IV DAN 2 mcg/kgBB IV TERHADAP TEKANAN DARAH DAN NADI AKIBAT INTUBASI JALAN NAFAS PADA PASIEN YANG MENJALANI PEMBEDAHAN ELEKTIF DI RSUP Prof. Dr. R. D. KANDOU MANADO PERIODE NOVEMBER - DESEMBER 2014
}

\author{
${ }^{1}$ Marsela J. A. Berhimpong \\ ${ }^{2}$ Harold Tambajong \\ ${ }^{2}$ Diana Ch. Lalenoh
}

\author{
${ }^{1}$ Kandidat Skripsi Fakultas Kedokteran Universitas Sam Ratulangi Manado \\ ${ }^{2}$ Bagian Ilmu Anestesi dan Terapi Intensif Universitas Sam Ratulangi Manado \\ Email: m.berhimpong_11_138@yahoo.com
}

\begin{abstract}
Intubation is a patent measure of securing and maintaining the airway. Fentanyl is a synthetic opioid that effectively blunts the sympathetic response to intubation and surgical stimulus. Fentanyl is often the primary choice of premedication and induction agent in general anesthesia due to its little depressant effect on cardiovascular system. Objective: To analyze the differences in blood pressure and pulse rate during intubation after administration of premedication fentanyl $1 \mathrm{mcg} / \mathrm{kg}$ iv premedication compared to fentanyl $2 \mathrm{mcg} / \mathrm{kg}$ iv. Methods: This is a prospective analytical study. The samples are 28 patients who were undergoing elective surgeries and were selected using purposive sampling method. The statistical test used is the average non-parametric test. Result: There is a change in blood pressure and pulse rate in patients who were given premedication fentanyl $1 \mathrm{mcg} / \mathrm{kg}$ iv and 2 $\mathrm{mcg} / \mathrm{kg}$ iv (p <0.05). The use of fentanyl $1 \mathrm{mcg} / \mathrm{kg}$ iv and $2 \mathrm{mcg} / \mathrm{kg}$ iv showed no significant difference ( $\mathrm{p}>0.05$ ), since both fentanyl $1 \mathrm{mcg} / \mathrm{kg}$ iv and $2 \mathrm{mcg} / \mathrm{kg}$ iv can lower both blood pressure and pulse rate. Conclusion: There is a change in blood pressure and pulse rate as a result of airway intubation in elective surgery patients who were given fentanyl $1 \mathrm{mcg}$ / kg iv and fentanyl $2 \mathrm{mcg} / \mathrm{kg}$ iv as premedications ( $\mathrm{p}<0.05$ ).
\end{abstract}

Keywords: intubation, fentanyl, blood pressure, pulse rate

\begin{abstract}
Abstrak: Intubasi merupakan tindakan pengaman dan pemeliharaan jalan nafas paling paten. Fentanil adalah opioid sintesis yang efektif menumpulkan respon simpatis pada intubasi serta stimulus pembedahan. Fentanil seringkali menjadi pilihan utama agen premedikasi dan induksi dalam anestesia umum karena sedikit mendepresi kardiovaskular. Tujuan: Untuk menganalisis perbedaan tekanan darah dan laju nadi pada tindakan intubasi setelah pemberian premedikasi fentanil $1 \mathrm{mcg} / \mathrm{kgbb}$ iv dibandingkan dengan premedikasi fentanil $2 \mathrm{mcg} / \mathrm{kgbb}$ iv. Metode penelitian: Penelitian ini merupakan penelitian analisis prospektif. Sampel ialah 28 pasien yang menjalani bedah elektif. Cara pengambilan sampel dilakukan dengan metode purposive sampling. Uji statistik menggunakan uji rerata non parametrik. Hasil penelitian: terdapat perubahan tekanan darah dan nadi pada pasien yang diberikan premedikasi fentanil 1 $\mathrm{mcg} / \mathrm{kgbb}$ iv dan $2 \mathrm{mcg} / \mathrm{kgbb}$ iv $(\mathrm{p}<0,05)$. Penggunaan fentanil $1 \mathrm{mcg} / \mathrm{kgbb}$ iv dan 2 $\mathrm{mcg} / \mathrm{kgbb}$ iv menunjukkan tidak terdapat perbedaan yang signifikan ( $>0,05)$, baik fentanil 1 $\mathrm{mcg} / \mathrm{kgbb}$ iv dan $2 \mathrm{mcg} / \mathrm{kgbb}$ iv keduanya dapat menurunkan tekanan darah dan laju nadi. Simpulan: Terdapat perubahan tekanan darah dan laju nadi akibat intubasi jalan nafas pada pasien pembedahan elektif yang diberikan premedikasi fentanil $1 \mathrm{mcg} / \mathrm{kgbb}$ iv dan fentanil 2 $\mathrm{mcg} / \mathrm{kgbb}$ iv $(\mathrm{p}<0,05)$.
\end{abstract}

Kata kunci: intubasi, fentanil, tekanan darah, laju nadi 
Pengelolaan jalan nafas merupakan tindakan yang penting dalam bidang anestesiologi, baik untuk operasi maupun pemberian ventilasi mekanik. ${ }^{1}$ Pemasangan pipa endotrakeal atau intubasi merupakan tindakan pengaman dan pemeliharaan jalan nafas paling paten. Intubasi paling banyak dilakukan menggunakan teknik laringoskopi. ${ }^{2,3}$

Berbagai penelitian dilakukan untuk mengetahui metode pencegahan gejolak hemodinamik pada saat laringoskopi dan intubasi. Diantaranya yaitu penggunaan berbagai teknik intubasi, pemilihan peralatan jalan nafas serta penambahan obat sebelum intubasi menggunakan lidokain, fentanil, remifentanil, alfentanil, penyekat beta, nifedipin, klonidin dan diltiazem. $^{1,4}$

Terdapat berbagai macam tehnik dan obat anestetik yang tersedia untuk mengontrol respon hemodinamik akibat tindakan laringoskopi dan intubasi. ${ }^{5-7}$ Beberapa obat yang sudah diteliti dapat menurunkan respon hemodinamik yang meningkat selama tindakan laringoskopi dan intubasi diantaranya: golongan opioid, alpa dan beta adrenergik, obat-obat vasodilator seperti sodium nitroprusside, angiotensin-converting enzim inhibitor, klonidin, penggunaan obat anestetik topikal pada orofaring, laring dan trakea, pemberian lidokain intravena dan anestesia inhalasi yang dalam. ${ }^{8,9}$ Menggunakan gas anestetik memiliki kerugian yakni gas anestesia pada umumnya mendepresi miokard, masa pemulihan semakin panjang sejalan dengan peningkatan konsentrasi gas anestetik. $^{10}$

Fentanil merupakan obat golongan opioid yang banyak digunakan sebagai anti nyeri. Ditemukan pada tahun 1960, fentanil telah di uji cobakan pada hewan sebelum digunakan pada manusia. Penelitian yang dilakukan oleh Lee dkk tahun 2000 menggunakan kucing sebagai sampel penelitian dengan tujuan penelitian untuk mengetahui farmakokinetik dan farmakodinamik fentanil. Hasil penelitian ini adalah konsentrasi plasma fentanil yang diberikan akan menurun setelah 2-3 jam.
Aplikasi klinis dari fentanil adalah fentanil dapat digunakan sebagai anti nyeri pada kucing setelah operasi besar dan bahkan bisa digunakan sebagai antinyeri jangka panjang pada kanker. ${ }^{11}$

Selain penelitian tersebut diatas, ada beberapa penelitian lain tentang penggunaan fentanil pada hewan seperti penelitian yang dilakukan oleh Carrol dkk, yang mengambil kambing sebagai sampel penelitian. Penelitian ini mengukur kadar konsentrasi plasma fentanil dengan hasil akhir yang hampir sama pada penelitian Lee dkk. ${ }^{12,13}$

Fentanil adalah opioid sintesis yang efektif dalam menumpulkan respon simpatis pada laringoskopi dan intubasi serta stimulus pembedahan. ${ }^{14}$ Penelitian Kauto dkk pada tahun 1982 mengatakan fentanil $2 \mathrm{mcg} / \mathrm{kgbb}$ iv secara signifikan menekan respon hemodinamik dan fentanil $6 \mathrm{mcg} / \mathrm{kgbb}$ iv secara sempurna menumpulkan respon hemodinamik jika diberikan satu setengah dan tiga menit sebelum intubasi, tetapi dosis ini dapat menimbulkan efek samping berupa bradikardi, hipotensi, rigiditas otot dan terlambat pulih. ${ }^{15}$ Penelitian Katoh dkk pada tahun 1999 mengatakan fentanil $4 \mathrm{mcg} / \mathrm{kgbb}$ iv menyebabkan perubahan denyut jantung dan tekanan darah lebih efektif dibandingkan fentanil $1 \mathrm{mcg} / \mathrm{kgbb}$ iv dan $2 \mathrm{mcg} / \mathrm{kgbb}$ iv dimana tidak ada perbedaan pada pemakaian fentanil $2 \mathrm{mcg} / \mathrm{kgbb}$ iv dan fentanil $4 \mathrm{mcg} / \mathrm{kgbb}$ iv dalam menurunkan konsentrasi sevoflurane yang dibutuhkan untuk intubasi. ${ }^{16}$

Penelitian yang dilakukan oleh Bessiere dkk menyatakan fentanil dapat mencegah hiperalgesia dan kecemasan. ${ }^{17}$ Karena sifat analgesia yang baik, onset yang cepat dan durasi yang singkat, sedikit mendepresi kardiovaskular serta tidak menyebabkan pelepasan histamin, maka fentanil seringkali menjadi pilihan utama agen premedikasi dan induksi dalam anestesia umum. ${ }^{18,19}$

Dari latar belakang tersebut, penelitian ini dilakukan untuk mengetahui perubahan tekanan darah dan laju nadi akibat tindakan intubasi pada premedikasi fentanil 1 
mcg/kgbb iv dan 2 mcg/kgbb iv. Perubahan hemodinamik yang tinggi dapat mempengaruhi kondisi pasien yang menjalani operasi. Rencana operasi yang dijadwalkan bisa saja dibatalkan akibat gejolak kardiovaskuler tersebut.

\section{METODE PENELITIAN}

Penelitian ini merupakan penelitian analisis prospektif. Sampel penelitian adalah pasien yang menjalani pembedahan elektif yang memenuhi kriteria inklusi dan eksklusi. Cara pengambilan sampel dilakukan dengan metode purposive sampling. Jumlah sampel sebesar 28 pasien. Data diolah dengan komputer menggunakan program SPSS for windows seri 20.

\section{HASIL PENELITIAN}

Hasil penelitian menyajikan analisis karakteristik umur responden dan tindakan yang dilakukan. Untuk mengetahui perubahan tekanan darah dan laju nadi pada tindakan intubasi setelah perlakuan dilakukan uji rerata non parametrik.

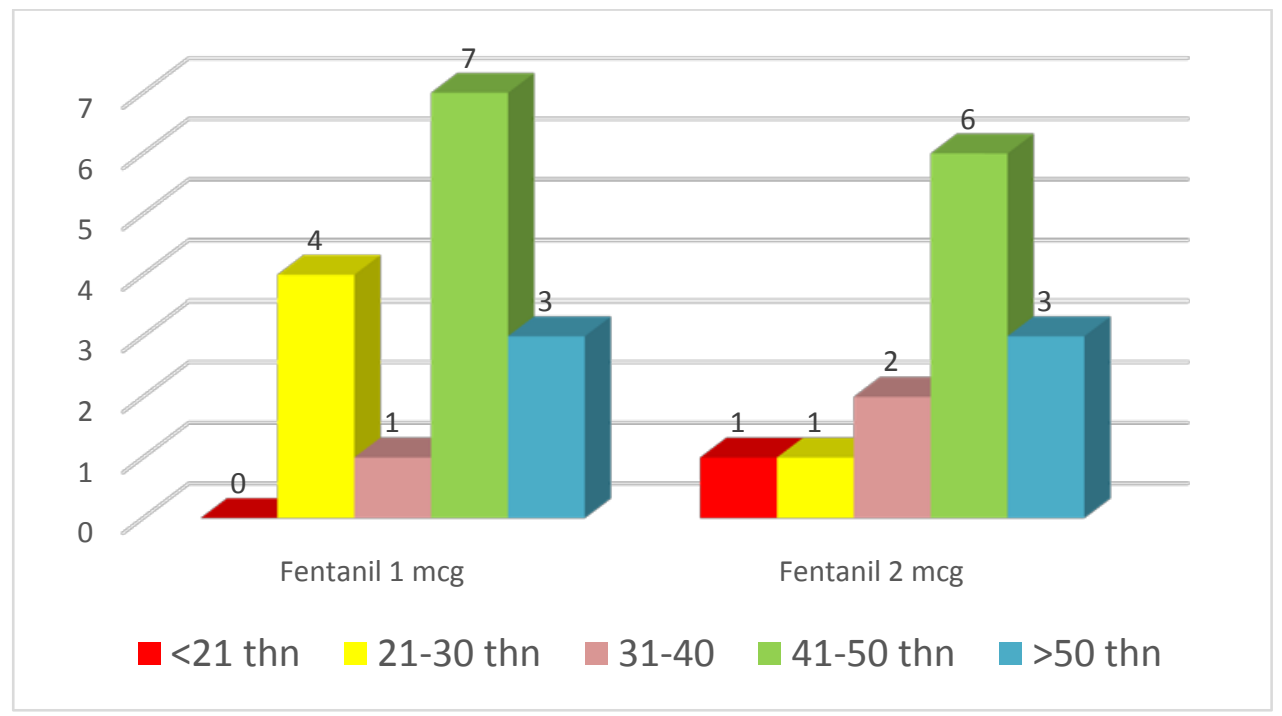

Gambar 1. Grafik Distribusi Umur Responden Berdasarkan Tindakan Premedikasi

Berdasarkan Gambar 1, dapat dilihat bahwa pada kelompok pemberian fentanil 1 $\mathrm{mcg} / \mathrm{kgbb}$ iv, sebagian besar responden berusia 41-50 tahun berjumlah 7 responden (46,7\%), dan pada kelompok pemberian fentanil $2 \mathrm{mcg} / \mathrm{kgbb}$ iv, sebagian besar responden berusia 41-50 tahun dengan jumlah 6 responden (46,2\%). Tabel 2 menunjukkan bahwa dari 13 responden dengan pemberian fentanil $2 \mathrm{mcg} / \mathrm{kgbb}$ iv, terdapat 2 tindakan yaitu Lap. VC dan MRM yang diterima oleh masing-masing 2 responden (15,4\%), sedangkan tindakan lainnya yaitu appendektomi, histerektomi totalis, HT radikal, miomektomi, MRM dextra, open cholesistektomi, revisi scar, subtotal tiroidektomi dan urolitotomi dextra masing-masing pada 1 responden (7,7\%).

Untuk mengetahui efek pemberian premedikasi fentanil terhadap perubahan hemodinamik akibat intubasi jalan nafas pada pasien yang menjalani pembedahan elektif di RSUP Prof. Dr. R.D. Kandou Manado periode November - Desember 2014, pada masing-masing premedikasi fentanil $1 \mathrm{mcg} / \mathrm{kgbb}$ iv dan $2 \mathrm{mcg} / \mathrm{kgbb}$ iv, dilakukan dengan Wilcoxon Signed Rank Test. Penggunaan uji rerata ini dilakukan berdasarkan asumsi normalitas data yang tersedia, dimana melalui uji normalitas dengan metode Saphiro Wilk diperoleh data yang tidak terdistribusi secara normal (Sig. $\mathrm{p}>0,05)$. 
Berhimpong, Tambajong, Lalenoh: Perbandingan premedikasi fentanil...

Tabel 1. Distribusi Jenis Tindakan Pemberian Fentanil 1 mcg/kgbb iv

\begin{tabular}{lcc}
\hline \multicolumn{1}{c}{ Tindakan } & $\mathrm{n}$ & $\%$ \\
\hline Debridemen & & \\
Eksisi Lipoma & 1 & 6,7 \\
Eksisi tumor & 1 & 6,7 \\
Eksisional Biopsi & 1 & 6,7 \\
Eksisipam & 1 & 6,7 \\
FESS dengan GA & 1 & 6,7 \\
Ishmolobektemi & 1 & 6,7 \\
Laparaskopik Koleksistektomi & 1 & 6,7 \\
Laparatomi & 1 & 6,7 \\
Miles Procedur & 1 & 6,7 \\
Orif & 1 & 6,7 \\
Relaparatomi Debulking & 1 & 6,7 \\
Relax dislokasi+skeletal traksi & 1 & 6,7 \\
Stabilisasi Posterior & 1 & 6,7 \\
Torakotomi & 1 & 6,7 \\
Total & 1 & 6,7 \\
\hline
\end{tabular}

Tabel 2. Distribusi Jenis Tindakan Pemberian Fentanil 2 mcg/kgbb iv

\begin{tabular}{lcc}
\hline \multicolumn{1}{c}{ Tindakan } & $\mathrm{n}$ & $\%$ \\
\hline Appendektomi & & \\
Histerektomi Totalis & 1 & 7,7 \\
HT Radikal & 1 & 7,7 \\
Lap VC & 1 & 7,7 \\
Miomektomi & 2 & 15,4 \\
MRM & 1 & 7,7 \\
MRM Dextra & 2 & 15,4 \\
Open cholesistektomi & 1 & 7,7 \\
Revisi Scar & 1 & 7,7 \\
Subtotal tiroidektomi & 1 & 7,7 \\
Urolitotomi Dextra & 1 & 7,7 \\
\multicolumn{1}{c}{ Total } & 1 & 7,7 \\
\hline
\end{tabular}

Tabel 3. Nilai Analisis Wilcoxon Signed Rank Test pada Pemberian Fentanil 1 mcg/kgbb iv

\begin{tabular}{cccc}
\hline Analisis & $\begin{array}{c}\text { Pre - Post } \\
\text { TD Sistolik }\end{array}$ & $\begin{array}{c}\text { Pre - Post } \\
\text { TD Diastolik }\end{array}$ & $\begin{array}{c}\text { Pre - Post } \\
\text { Nadi }\end{array}$ \\
\hline Z & 3,410 & 3,352 & 3,501 \\
Sig. $(p)$ & 0,001 & 0,001 & 0,000 \\
\hline
\end{tabular}


Berdasarkan Tabel 3 dapat dilihat hasil nilai analisis Wilcoxon Signed Rank Test pada pemberian fentanil $1 \mathrm{mcg} / \mathrm{kgbb}$ iv. Nilai signifikan TDS sebelum dan setelah diberikan fentanil $1 \mathrm{mcg} / \mathrm{kgbb}$ iv adalah $\mathrm{p}=0.001$, jika dibandingkan dengan penggunaan $\alpha 5 \%(0,05)$, maka $p=0,001<$ 0,05. Hasil ini menunjukkan bahwa Hipotesis 1 (H1) diterima, yaitu terdapat perubahan TDS sebelum dan setelah premedikasi fentanil $1 \mathrm{mcg} / \mathrm{kgbb}$ iv. Nilai signifikan TDD sebelum dan setelah diberikan fentanil $1 \mathrm{mcg} / \mathrm{kgbb}$ iv adalah $\mathrm{p}=$ 0.001, jika dibandingkan dengan penggunaan $\alpha 5 \%(0,05)$, maka $\mathrm{p}=0,001<$ 0,05. Hasil ini menunjukkan bahwa Hipotesis 1 (H1) diterima, yaitu terdapat perubahan TDD sebelum dan setelah premedikasi fentanil $1 \mathrm{mcg} / \mathrm{kgbb}$ iv. Nilai signifikan nadi sebelum dan setelah diberikan fentanil mcg/kgbb iv adalah $\mathrm{p}=$ 0.000, jika dibandingkan dengan penggunaan $\alpha 5 \%(0,05)$, maka $p=0,001<$ 0,05. Hasil ini menunjukkan bahwa Hipotesis 1 (H1) diterima, yaitu terdapat perubahan nadi sebelum dan setelah premedikasi fentanyl $1 \mathrm{mcg} / \mathrm{kgbb}$ iv.
Berdasarkan Tabel 4 dapat dilihat hasil nilai analisis Wilcoxon Signed Rank Test pada pemberian fentanil $2 \mathrm{mcg} / \mathrm{kgbb}$ iv. Nilai signifikan TDS sebelum dan setelah diberikan fentanil $2 \mathrm{mcg} / \mathrm{kgbb}$ iv adalah $\mathrm{p}=$ 0.001, jika dibandingkan dengan penggunaan $\alpha 5 \%(0,05)$, maka $\mathrm{p}=0,001<$ 0,05. Hasil ini menunjukkan bahwa Hipotesis 1 (H1) diterima, yaitu terdapat perubahan TDS sebelum dan setelah premedikasi fentanil $2 \mathrm{mcg} / \mathrm{kgbb}$ iv. Nilai signifikan TDD sebelum dan setelah diberikan fentanil $2 \mathrm{mcg} / \mathrm{kgbb}$ iv adalah $\mathrm{p}=$ 0.001, jika dibandingkan dengan penggunaan $\alpha 5 \%(0,05)$, maka $\mathrm{p}=0,001$ $<0,05$. Hasil ini menunjukkan bahwa Hipotesis 1 (H1) diterima, yaitu terdapat perubahan TDD sebelum dan setelah premedikasi fentanil 2 mcg/kgbb iv. Nilai signifikan nadi sebelum dan setelah diberikan fentanil mcg/kgbb iv adalah $\mathrm{p}=$ 0.023, jika dibandingkan dengan penggunaan $\alpha 5 \%(0,05)$, maka $p=0,023<$ 0,05. Hasil ini menunjukkan bahwa Hipotesis 1 (H1) diterima, yaitu terdapat perubahan nadi sebelum dan setelah premedikasi fentanil $2 \mathrm{mcg} / \mathrm{kgbb}$ iv.

Tabel 4. Nilai Analisis Wilcoxon Signed Rank Test pada Pemberian Fentanil 2 mcg/kgbb iv

\begin{tabular}{cccc}
\hline Analisis & $\begin{array}{c}\text { Pre }- \text { Post } \\
\text { TD Sistolik }\end{array}$ & $\begin{array}{c}\text { Pre - Post } \\
\text { TD Diastolik }\end{array}$ & $\begin{array}{c}\text { Pre }- \text { Post } \\
\text { Nadi }\end{array}$ \\
\hline Z & 3,181 & 2,972 & 2,267 \\
Sig. $(p)$ & 0,001 & 0,001 & 0,023 \\
\hline
\end{tabular}

Tabel 5. Perbedaan Premedikasi Fentanil 1 mcg/kgbb iv dan Fentanil 2 mcg/kgbb iv

\begin{tabular}{ccccccc}
\hline Test & Pre & Post & Pre & Post & Pre & Pre \\
& TDS & TDS & TDD & TDD & Nadi & Nadi \\
\hline $\mathrm{Z}$ & 1,567 & 0,277 & 1,362 & 0,392 & 0,277 & 1,170 \\
& & & & & & \\
$p$ & 0,117 & 0,172 & 0,851 & 0,782 & 0,695 & 0,242 \\
\hline
\end{tabular}


Tabel 5 menunjukkan tentang perbedaan hasil premedikasi fentanil 1 $\mathrm{mcg} / \mathrm{kgbb}$ iv dan fentanil $2 \mathrm{mcg} / \mathrm{kgbb}$ iv. Uji yang digunakan untuk melihat perbedaan ini adalah uji non parametrik Mann-Whitney U Test. Penggunaan uji ini dilakukan karena melalui metode Saphiro Wilk diperoleh sebaran data tidak terdistribusi secara normal $(\mathrm{p}<0,05)$. Hasil analisis menunjukkan tidak ada perbedaan premedikasi fentanil $1 \mathrm{mcg} / \mathrm{kgbb}$ iv dan fentanil $2 \mathrm{mcg} / \mathrm{kgbb}$ iv, keduanya dapat menurunkan tekanan darah dan laju nadi. Hal ini ditunjukkan dengan nilai signifikansi $\mathrm{p}>0,05$ untuk semua jenis pengukuran tekanan darah dan laju nadi baik sebelum dan setelah diberikan premedikasi fentanil $1 \mathrm{mcg} / \mathrm{kgbb}$ iv dan fentanil $2 \mathrm{mcg} / \mathrm{kgbb}$ iv pada pasien yang menjalani pembedahan elektif di RSUP Prof. Dr. R.D. Kandou Manado periode November - Desember 2014.

\section{BAHASAN}

Berdasarkan data pada gambar 1 diperoleh sebagian besar responden penelitian adalah berumur 41-50 tahun baik itu pada premedikasi fentanil $1 \mathrm{mcg} / \mathrm{kgbb}$ iv dan fentanil $2 \mathrm{mcg} / \mathrm{kgbb}$ iv. Pada tabel 1 memperlihatkan sebanyak 15 tindakan yang berbeda bagi masing-masing responden yang berjumlah 15 orang pada premedikasi fentanil $1 \mathrm{mcg} / \mathrm{kgbb}$ iv. Pada tabel 2 memperlihatkan sebanyak 11 tindakan yang berbeda bagi responden yang berjumlah 13 orang pada premedikasi fentanil $2 \mathrm{mcg} / \mathrm{kgbb}$ iv.

Hasil analisis deskriptif pada gambar 2 menunjukkan perbandingan rata-rata tekanan darah sistolik, tekanan darah diastolik dan nadi dengan premedikasi fentanil $1 \mathrm{mcg} / \mathrm{kgbb}$ iv, yang menunjukkan terdapat perubahan nilai tekanan darah diastolik. Sebelum diberikan fentanil nilai rata-rata tekanan darah diastol adalah 139,3, setelah diberikan fentanil turun menjadi 118,3. Hal ini menunjukkan adanya pengaruh pemberian fentanil terhadap penurunan tekanan darah diastolik. Demikian juga pada tekanan darah sistolik dimana nilai sebelum premedikasi adalah 83,3, setelah diberikan premedikasi turun menjadi 72,1. Pada nadi, sebelum diberikan premedikasi, nilai ratarata nadi adalah 96,7, setelah diberikan turun menjadi 94,6. Proses penurunan pada dosis fentanil $1 \mathrm{mcg} / \mathrm{kgbb}$ iv juga terjadi pada dosis fentanil $2 \mathrm{mcg} / \mathrm{kgbb}$ iv. Nilai rata-rata tekanan darah sistolik sebelum premedikasi adalah 149,3, setelah diberikan premedikasi turun menjadi 117,6 , nilai ratarata tekanan darah diastolik sebelum premedikasi adalah 89,3, setelah diberikan premedikasi turun menjadi 73,7 , nilai ratarata nadi sebelum premedikasi adalah 97,9, setelah diberikan premedikasi turun menjadi 96.

Kauto dkk pada tahun 1982 dalam penelitiannya mengatakan fentanil 2 mcg/kgbb iv secara signifikan menekan respon hemodinamik dan fentanil 6 $\mathrm{mcg} / \mathrm{kgbb}$ iv secara sempurna menumpulkan respon hemodinamik yang diberikan sebelum intubasi. ${ }^{15}$ Pada hasil penelitian ini menunjukkan terdapat perubahan tekanan darah dan nadi pada pasien yang menjalani pembedahan elektif di RSUP Prof. Dr. R.D. Kandou Manado periode November - Desember 2014 (p < 0,05). Perlakuan dengan metode pre post menunjukkan hasil yang berbeda akibat pemberian premedikasi fentanil 1 $\mathrm{mcg} / \mathrm{kgbb}$ iv dan $2 \mathrm{mcg} / \mathrm{kgbb}$ iv.

Fentanil adalah opioid sintesis yang efektif dalam menumpulkan respon simpatis pada laringoskopi dan intubasi serta stimulus pembedahan. ${ }^{14}$ Karena sifat analgesia yang baik, onset yang cepat dan durasi yang singkat, sedikit mendrepresi kardiovaskular, maka fentanil sering menjadi pilihan utama agen premedikasi dan induksi umum. ${ }^{18,19}$ Penggunaan fentanil $1 \mathrm{mcg} / \mathrm{kgbb}$ iv dan $2 \mathrm{mcg} / \mathrm{kgbb}$ iv menunjukkan tidak terdapat perbedaan yang signifikan. Hasil penelitian menunjukkan bahwa baik fentanil 1 $\mathrm{mcg} / \mathrm{kgbb}$ iv dan $2 \mathrm{mcg} / \mathrm{kgbb}$ iv, keduanya dapat menurunkan tekanan darah dan laju nadi melalui metode pre post pada pasien proses pembedahan $(\mathrm{p}>0,05)$. Suryajaya dalam penelitian tentang penggunaan fentanil $1 \mathrm{mcg} / \mathrm{kgbb}$ iv dibandingkan 
dengan lidocain $1 \mathrm{mcg} / \mathrm{kgbb}$ iv, didapatkan tidak terdapat perbedaan perubahan hemodinamik saat intubasi pada cidera otak. $^{20}$

Fentanil dengan dosis $1-2 \mathrm{mcg} / \mathrm{kgbb}$, dapat digunakan untuk analgesik preoperatif. Terdapat preparat fentanil dalam bentuk oral transmukosa dengan dosis 5-20 mcg/kgbb. Bentuk ini dapat digunakan sebagai premedikasi pada orang dewasa dan anak-anak untuk mengurangi kecemasan dan nyeri. Fentanil dalam bentuk oral transmukosa tidak direkomendasikan untuk anak dibawah 6 tahun sebagai preoperatif karena dapat menyebabkan mual dan muntah. Fentanil dapat menyebabkan depresi miokard dan pelepasan histamin dan mungkin menyebabkan depresi ventilasi dan bradikardi. $^{21}$

\section{SIMPULAN}

Berdasarkan hasil penelitian dan pembahasan, maka ditarik kesimpulan sebagai berikut:

1. Terdapat perubahan tekanan darah dan laju nadi akibat intubasi jalan nafas pada pasien pembedahan elektif yang mendapat premedikasi fentanil 1 $\mathrm{mcg} / \mathrm{kgbb}$ iv $(\mathrm{p}<0,05)$

2. Terdapat perubahan tekanan darah dan laju nadi akibat intubasi jalan nafas pada pasien pembedahan elektif yang mendapat premedikasi fentanil 2 mcg/kgbb iv ( $<<0,05)$.

3. Tidak terdapat perbedaan premedikasi fentanil $1 \mathrm{mcg} / \mathrm{kgbb}$ iv dan fentanil 2 mcg/kgbb iv pada pasien yang menjalani pembedahan elektif di RSUP Prof. Dr. R.D. Kandou Manado $(p>0,05)$.

\section{SARAN}

Perlu dilakukan penelitian lagi yang lebih lanjut dengan jumlah sampel yang lebih banyak.

\section{DAFTAR PUSTAKA}

1. Airway Management. In: Morgan GE, Mikhail MS, Murray MJ, editors. Clinical Anesthesiology. 4th ed. New
York. McGraw-Hill; 2006; 91-116

2. Hagberg C, Georgi R, Krier C. Complications of managing the airway. Best Practice \& Research Clinical Anaesthesiology. 2005; 19(4): 641-59

3. Sener EB, Ustun E, Sarihasan B. Hemodynamic responses and upper airway morbidity following tracheal intubation in patients with hypertension: Conventional laryngoscopy versus an intubating laryngeal mask airway. Clinics. 2012; 67(1): 49-54

4. Mohseni G, Kolyaei A, Farshchian M, Rezaei M, Ghadami N. Comparison between effects of intravenous lidocaine and sublingual nifedipine on preventing blood pressure increase in laryngoscopy. Open Access Journal of Clinical Trials. June 2010; 2: 89-92

5. Yushi U. A, Maiko Satomoto, Hideyuki Higuchi, Kazuhiko Watnabe. Fentanyl attenuate the hemodynamic response to endotracheal intubation more than the response to laryngoskopi. Anesth Analg. 2002; 95: 233-7

6. Hung Orlando. Understanding hemodynamic response to tracheal intubation. Can J Anesth. 2001; 48(8): 723-36

7. Malde D. Anila, Sarode Vineet. Attenuate of the hemodynamic response to tracheal intubation fentanyl versus lignocain. The Internet Journal of Anesthesiology. 2007; 12(1): 173-6

8. Roelofse J. A, Shipton E. A, Grotepass F. W. A comparison of labetalol, acebutalol, and lidocaine for controlling the cardiovascular response to endotracheal intubation for oral surgical procedures. J Oral Maxillofac Surg. 1987; 45: 835-40

9. Kindler H. Cristoph, Schumacher G. Philippe, Schneider C. Markus. Effect of intravenous lidocaine and/or esmolol on hemodynamic response to laryngoscopy and intubation: A double blind controlled clinical trial. J. Clin. Anesth, 1996; 8:491-96

10.Munoz HR, Altermatt FR, Gonzalez JA, Leon PJ. The effect of different isoflurane-fentanyl dose combination 
on early recovery from anaesthesia and post operatif adverse effect. Anesth Analg. 2005; 101:371-76

11.Lee DD, Parich MG, Hardie EM. Comparison of pharmacokinetics of fentanyl after intravenous and transdermal administration in cats. Am J Vet Res, 2000; 61(6): 672-7

12.Carrol GL, Hooper RN, Boothe DM, Hartsfeld SM, Radoll LA. Pharmacokinetics of fentanyl after intravenous and transdermal administration in goats. Am $\mathrm{J}$ Vet Res, 1994; 60(8): 986-91

13.Ahern BJ, Soma LR, Rudy JA, Uboh CE, Schaer TE. Pharmacokinetic of fentanyl administered transdermally and intravenously in sheep. Am J Vet Res, 2010; 71(10): 1127-32

14.Ferguson L. M, Drummond G. B. Acute effect of fentanyl on breathing pattern anaesthetized subject. $\mathrm{Br} \quad \mathrm{J}$ ANAESTH. 2006; 96(3): 384-90

15.Kautto. Attenuation of the circulatory response to laryngoscopy and intubation by fentanyl. Acta Anaesth Scand. 1982; 26(3): 217-21

16.Katoh T, Nakajima Y, Moriwaki G, Kobayashi S, Suzuki A, Iwamoto T, et al. Sevoflurance requirements for tracheal intubation with and without fentanyl. BR J Anaesth. 1999; 82(43): 561-5

17.Bessiere B, Richebe $P$, Contarino A, Laboureyras E, Laulin JP. Fentanyl induces both long-lasting hyperalgesia and anxiety. European Journal of Anaesthesiology. June 2006; 230

18.Egan TD. Opioids In: Miller RD, Pardo MC, editors. Basics of Anesthesia 6th ed. Philadelphia: Elseiver; 2011. p.115-25

19.Coda BA. Opioids. In: Barash PG, Cullen $\mathrm{BF}$, Stoelting RK, editors. Clinical Anesthesia 5th ed. Philadelphia: Lippincott Williams \& Wilkins; 2006. p.353-83

20.I Wayan Suryajaya. Perbandingan efek lidocain dengan fentanyl terhadap perubahan hemodinamik saat intubasi pada cidera otak. Fakultas Kedokteran UNAIR; 2010

21.Thomas Henry, Juliana, Runtika Dewi, Beriman Parhusip, Alman. Pengobatan Preoperatif. 2009. Available from: http://www.docstoc.com/docs/780413 2/Premedikasi 